\title{
The Expression of MaEXP1, a Melilotus alba Expansin Gene, Is Upregulated During the Sweetclover-Sinorhizobium meliloti Interaction
}

\author{
Walter Giordano ${ }^{1}$ and Ann M. Hirsch ${ }^{1,2}$ \\ ${ }^{1}$ Department of Molecular, Cell, and ${ }^{2}$ Developmental Biology and Molecular Biology Institute, University of California, \\ Los Angeles 90095-1606, U.S.A.
}

Submitted 15 September 2003. Accepted 28 January 2004.

Expansins are a highly conserved group of cell wall-localized proteins that appear to mediate changes in cell wall plasticity during cell expansion or differentiation. The accumulation of expansin protein or the mRNA for specific expansin gene family members has been correlated with the growth of various plant organs. Because expansin proteins are closely associated with plant cell wall expansion, and as part of a larger study to determine the role of different gene products in the legume-Rhizobium spp. symbiosis, we investigated whether a Melilotus alba (white sweetclover) expansin gene is expressed during nodule development. A cDNA fragment encoding an expansin gene (EXP) was isolated from Sinorhizobium meliloti-inoculated sweetclover root RNA by reverse-transcriptase polymerase chain reaction using degenerate primers, and a full-length sweetclover expansin sequence (MaEXP1) was obtained using $5^{\prime}$ and $3^{\prime}$ rapid amplification of cDNA end cloning. The predicted amino acid of the sweetclover expansin is highly conserved with the various $\alpha$-expansins in the GenBank database. MaEXP1 contains a series of eight cysteines and four tryptophans that are conserved in the $\alpha$-expansin protein family. Northern analysis and whole-mount in situ hybridization analyses indicate that MaEXP1 mRNA expression is enhanced in roots within hours after inoculation with $S$. meliloti and in nodules. Western and immunolocalization studies using a cucumber expansin antibody demonstrated that a cross-reacting protein accumulated in the expanding cells of the nodule.

Additional keywords: cell elongation or expansion.

Many legumes respond to Rhizobium spp. inoculation by developing new organs known as root nodules. The development of a legume nodule in which rhizobia convert atmospheric nitrogen into ammonia requires the exchange of specific signal molecules between the host plants and their microsymbionts. Flavonoids released by plant roots or seed are believed to act as chemoattractants to the bacteria, and certain flavonoids also are known to induce rhizobial (nod) genes. The products of rhizobial nod genes synthesize a lipochitooligosaccharide molecule known as Nod factor (Lerouge et al. 1990), which, in the appropriate legume, induces a variety of effects, including deformation of root hairs, division of root cortical cells, and nodule morphogene-

Corresponding author: Ann M. Hirsch, Telephone: 1.310.206.8673; Fax: 1.310.206.5413; E-mail: ahirsch@ucla.edu sis (Perret et al. 2000), in addition to the expression of several early nodulin (ENOD) genes (Downie and Walker 1999). Legumes are unique in the extent of their responses to Nod factor signals. Although considerable progress has been made in understanding the molecular biology, genetics, and biochemistry of the bacterial partner, the molecular mechanisms of nodule organogenesis programmed in the host legume plant are still imperfectly understood.

Plant growth is the result of cell division and cell enlargement, and is accompanied by an increase in plasma membrane and cell wall surface area. The enlargement of plant cells requires shearing and slippage of structural polymers within the cell wall, which must simultaneously maintain sufficient strength to withstand high turgor forces. The walls of expanding vegetative tissues possess numerous enzyme activities that may contribute to a modification of cell wall mechanical properties. Although cell wall hydrolases and transglycosylases are involved in disassembly of the cell wall during fruit ripening and organ abscission (Rose and Bennett 1999), their importance for cell wall enlargement is less clear. However, among the cell wall proteins studied to date, expansins are unique in their ability to induce immediate cell wall extension in vitro and cell expansion in vivo (Cosgrove 1999). This capacity to extend the cell wall is lost upon denaturation of wall protein (Cosgrove 1989). Heat-inactivated walls can be induced to elongate, however, by applying a protein extract from growing walls or by addition of purified expansins (McQueen-Mason et al. 1992). Nevertheless, the mode of action of expansin in cell wall loosening is not well understood. Biochemical and biophysical data suggest that expansin affects the stability of hydrogen bonds between cellulose and hemicellulose microfibrils, thereby controlling the rigidity of the cell wall (Cosgrove 1998). Accordingly, expansins can induce loosening of pure cellulosic paper (McQueen-Mason and Cosgrove 1994).

Expansin genes fall into three subfamilies, $\alpha-, \beta-$, and $\gamma-$ expansins (although the latter have not yet been shown to have wall-loosening activity) (Cosgrove et al. 2002), and appear to have an ancient evolutionary origin (Li et al. 2002). Expansin activity has been established in monocots, eudicots (Cosgrove 2000a), suspension-cultured cells (Link and Cosgrove 1998), gymnosperms (Li et al. 2002), ferns (Kim et al. 2000), and the green alga genus Nitella (Metraux and Taiz 1977). In Arabidopsis thaliana, expansins are members of a large gene family where 26 distinct $\alpha$-expansin genes have been identified ( $\mathrm{Li}$ et al. 2002). A total of 38 expansin or expansin-like sequences are present in Arabidopsis thaliana (Li et al. 2002).

As yet, only a few expansin genes have been characterized in legume plants. This is likely to change with the completion 
of the various legume genome projects. A detailed study of expansins in soybean demonstrated that GmEXP1 is expressed at high levels in roots, especially in the root elongation zone (Lee et al. 2003). Because expansins are proteins that induce extension of isolated cell walls and because they have been correlated with the growth of various plant organs, they are very likely to be involved in nodule development in the legumeRhizobium spp. symbiosis. Previously, Györgyey and associates (2000) identified an expansin gene that is expressed in young Medicago truncatula nodules induced by Sinorhizobium meliloti. However, expansin expression patterns have not been studied in roots following rhizobial inoculation or during nodule development. Here, we describe the expression of an $\alpha$-expansin gene in Melilotus alba (white sweetclover) as well as transcript and protein localization during the development of the nitrogen-fixing symbiosis with rhizobia.

\section{RESULTS}

Cloning and sequence analysis of MaEXP1.

To search for expansin genes involved in the $M$. alba-S. meliloti symbiosis, we used the reverse transcriptase version of the polymerase chain reaction (RT-PCR), utilizing degenerate primers corresponding to conserved regions of nine $\alpha$-expansin messages (Shcherban et al. 1995), to amplify $\alpha$-expansin cDNA fragments from roots nodulated by the $S$. meliloti strain Rm1021. The RT-PCR product migrated as a single band on an agarose gel (data not shown). Bands were collected and subsequently cloned, and the inserts of 16 different subclones were sequenced. Sequence analysis revealed that only one cDNA with homology to $\alpha$-expansin was amplified. The sequence was found to be $537 \mathrm{bp}$ in length and was deposited in GenBank (accession no. AY046875). A BLAST search (Altschul et al. 1997) of the database showed a high level of similarity to $\alpha$-expansin.

A putative full-length cDNA sequence was constructed from the overlapping DNA fragments of $537 \mathrm{bp}$ and its corresponding $5^{\prime}$ and $3^{\prime}$ RACE products. The clone was designated Melilotus alba expansin 1 (MaEXPl) and was deposited in the GenBank database (accession no. AF510987). MaEXPl is $1,282 \mathrm{bp}$ in length. The cDNA clone consists of a $5^{\prime}$-untranslated region of $96 \mathrm{bp}$, an open reading frame of $771 \mathrm{bp}$ encoding a polypeptide of 257 amino acids, and a 3 '-untranslated region of $415 \mathrm{bp}$.

The sequence of $M a E X P 1$ is highly conserved with those from other $\alpha$-expansins recorded in GenBank. Sequence analysis revealed $79,79,70$, and $62 \%$ identity and 88, 86, 80 and $72 \%$ similarity at the amino acid level to the predicted $\alpha$ expansin proteins of Pisum sativum (PsEXP1), Glycine max (GmEXP2), Cucumis sativa (CsEXP1), and $G$. max (GmEXP1), respectively (Fig. 1A). The $\alpha$-expansins so far identified have a signal peptide (approximately 25 amino acid residues) and possess eight conserved cysteines in their N-terminal regions and four conserved tryptophan residues in their C-terminal regions (Shcherban et al. 1995). According to the SignalP program, the deduced protein sequence of MaEXP1 was predicted to contain an N-terminal signal peptide of 25 able cysteine and tryptophan residues was strictly conserved in the sequence (Fig. 1A).

\section{Genomic analysis of MaEXP1.}

A cDNA fragment corresponding to part of the MaEXP1 coding region was used as a probe for genomic DNA gel-blot analysis (Fig. 1B). The probe hybridized to a single genomic fragment after high-stringency washes, suggesting that there is a single-copy gene in white sweetclover and that the probe is gene specific. Additional bands were present after lower-strin- gency washes (data not shown); these may represent genes that are not closely related to previously described $\alpha$-expansin genes of legumes.

Taken together, our sequence analysis indicates that the $M a E X P 1$ encodes an $\alpha$-expansin protein and, furthermore, that $M a E X P 1$, similar to its soybean counterparts, GmEXPl and $G m E X P 2$ (Lee et al. 2003), may exist as a single-copy gene.

\section{Transcript accumulation in roots following inoculation.}

The level of MaEXPl transcript accumulation was analyzed in roots at different time points after inoculation with $S$. meliloti (Fig. 2). Basal expression levels were detected in uninoculated roots. Before 5 days postinoculation (dpi), the level of MaEXP1 transcript accumulation was not significantly different from that of uninoculated roots based on Northern analysis (data not shown). Increased accumulation of MaEXPl transcripts was observed in roots inoculated with $S$. meliloti 5 dpi and thereafter, indicating that the increase in transcript levels of this gene is symbiotically enhanced. The highest level of $M a E X P 1$ transcript accumulation in nodulated root systems was detected at 15 to $20 \mathrm{dpi}$ (Fig. 2).

Because neither Northern nor RT-PCR analysis appeared to be sensitive enough to detect MaEXPl gene expression in uninoculated versus inoculated roots at early time points after inoculation, we undertook a whole-mount in situ hybridization (WISH) analysis to detect whether there was a difference in the accumulation of expansin transcripts at early time points.

At the 5- and 12-h time points, there was greater MaEXPl transcript accumulation in the Rm1021-inoculated roots than in the mock-inoculated control roots (Fig. 3A through D). By $24 \mathrm{~h}$ postinoculation (hpi), both the control and rhizobial inoculated roots demonstrated similar amounts of transcript accumulation based on the WISH results (Fig. 3E and F). At $24 \mathrm{hpi}$, the root hairs were deformed and cell expansion was observed behind the root tip. However, some cell expansion also was observed in the control roots. White sweetclover roots grown on agar for 24 to $48 \mathrm{~h}$ frequently bulge just behind the apical meristem. This region of cell expansion was coincident with the most intense color reaction.

The spatial pattern of gene expression in the root elongation zone persisted up to 5 days when the experiment was terminated (Fig. 3G through M). This profile of localization is consistent with the published findings for GmEXPl (Lee et al. 2003). MaEXP1 mRNA localization also was detected in the zone where root hairs are initiated and in the region distal to the elongation zone, but not in the meristem itself. Several of the root tips were paraffin-embedded and then sectioned at 10 $\mu \mathrm{m}$. An analysis of these sections demonstrated that MaEXPl transcripts were highly expressed in the epidermis (Fig. 3N, arrow), but no obvious color indicating MaEXPl expression was detected in the root hairs. MaEXPl transcripts were detected in the root meristem and the cells proximal to it, but at a lower level than in the root epidermis.

MaEXPl mRNAs also were identified in lateral roots (Fig. 3P and Q). A cross section through an emergent lateral root primordium showed that transcripts accumulated in the root epidermis (Fig. 3O, arrow).

\section{$M a E X P 1$ expression is not root specific.}

$M a E X P 1$ expression was examined at the level of mRNA abundance in sweetclover vegetative tissues. RNA gel-blot analysis using total RNA from leaf, stem, root, and nodule revealed a band of approximately $1.2 \mathrm{~kb}$ (Fig. 4). The strongest hybridization signal was detected in nodule RNA, but a relatively robust signal was found in stem and root RNA. Minimal $M a E X P 1$ transcript accumulation was detected in leaves. 

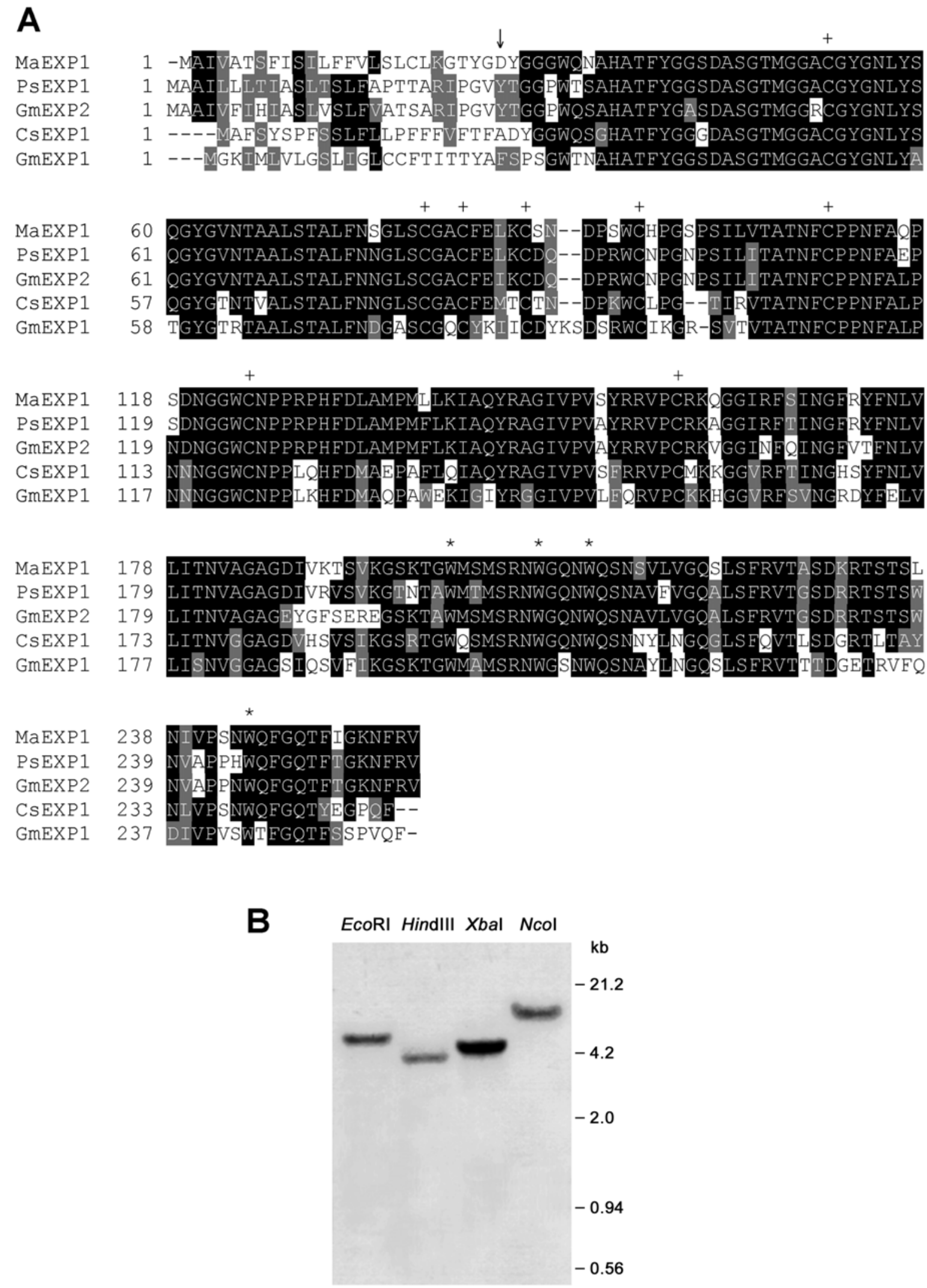

Fig. 1. A, Multiple alignment of the deduced amino acid sequence of the full-length sweetclover expansin cDNA. Deduced amino acid sequences for sweetclover MaEXP1 (accession no. AF510987), pea PsEXP1 (accession no. X85187), soybean GmEXP2 (accession no. AF516880), cucumber CsEXP1 (accession no. U30382), and soybean GmEXP1 (accession no. AF516879) were aligned using the Clustal-W 1.8 program. Amino acids printed in black boxes represent positions where at least $50 \%$ of the residues are identical. Amino acids that are similar to the consensus are shaded. Conserved cysteine (C) and tryptophan (W) residues are marked by crosses and asterisks, respectively. The location of the putative $\mathrm{N}$ terminus of the mature peptide from white sweetclover as predicted by the SignalP program is indicated by an arrow $(\downarrow)$. B, Genomic DNA analysis of MaEXP1. Genomic DNA was digested with the indicated restriction enzymes. The gel blot was hybridized with the MaEXP1 cDNA probe and washed under high-stringency conditions. 
Transcript accumulation in nodules.

Using the spot inoculation method, nodule primordia could be detected as early as $3 \mathrm{dpi}$. Both root and nodule primordia showed an overall light-purple color after the WISH procedure (Fig. 3Q). In slightly older nodule primordia (4 and 5 dpi), however, MaEXPl transcripts were found to be localized to the outermost cells of the nodule (Fig. 3R and S). When the WISH-stained nodule was sectioned, the blue-purple color indicating MaEXP1 mRNAs was restricted to the cells at the edge of the developing nodule (Fig. 3T). Many of these cells were small and densely cytoplasmic.

MaEXP1 gene expression in a fully developed (15 dpi) nodule appeared to be localized to the innermost cells of the nodule cortex, the nodule meristem, and the invasion zone (Fig. $5 \mathrm{~A})$. A very young nodule primordium emerging from the same lateral root showed mRNA localization over the entire primordium (Figs. 5A, arrow, and 3R and Q). Nodules harvested $20 \mathrm{dpi}$ and then hybridized with the antisense MaEXPl RNA probe showed patterns of transcript accumulation that were similar to the 15-dpi nodules in the youngest nodule cortex cells, in the cells of the nodule meristem (zone I) and the invasion zone (zone II), which lies directly adjacent to the meristem (Fig. 5B). The latter zone is the region where infection thread growth, release of rhizobia, and host cell expansion occur. The nodule illustrated in Figure 5B was cut in half following the WISH procedure, showing that the nodule interior was accessible to the probe. Transcripts also were detected in interzone II-III cells (Fig. 5B, bracketed), where rhizobial proliferation and continued enlargement of infected cells take place. Transcript accumulation tapered off in zone III. Generally, very little mRNA accumulation was detected in cells of the symbiotic zone (zone III) or in cells of the senescent zone (zone IV) (Fig. 5A through C). Sense MaEXP1 mRNA probes showed no signal above background (Fig. 5E).

There was some variability in transcript localization; some nodules exhibited less MaEXPl transcript accumulation in zone II (Fig. 5C). Paraffin-embedded, sectioned nodules confirmed that MaEXPl transcripts were detected in the nodule cortex, especially in the youngest cells adjacent to the nodule meristem, and in the nodule meristem itself (Fig. 5D), albeit at low levels. A blue-purple color also is observed in the infected cells of zone III in this nodule. Other nodules showed a similar pattern of transcript localization (data not shown).

In summary, MaEXPl transcripts accumulate in the youngest cells of the nodule cortex, in the nodule meristem, in zone

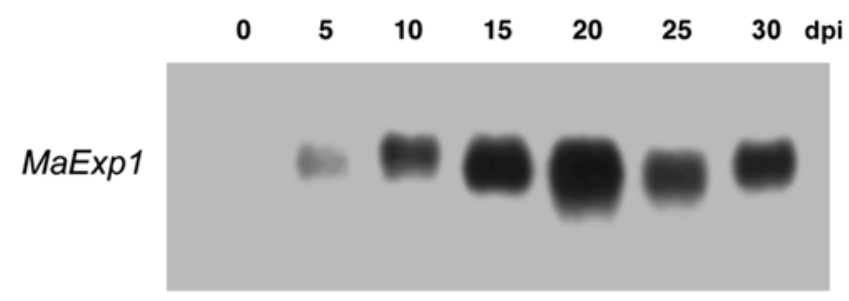

rRNA

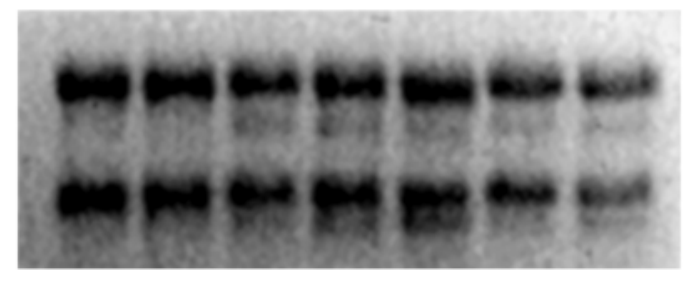

Fig. 2. Expression of expansin RNA in roots. A northern blot was prepared from $10 \mu \mathrm{g}$ of total RNA isolated from Melilotus alba roots 0 to 30 days postinoculation (dpi) with Sinorhizobium meliloti and then probed with the $M a E X P 1$ probe. Amounts of ribosomal RNA were confirmed by staining the gel with ethidium bromide.
II, and in interzone II-III of the nodule. There is a decrease in $M a E X P 1$ transcript accumulation in zone III, the nitrogen-fixing zone of the nodule.

\section{Immunodetection of expansin proteins in nodules.}

We next determined the location of a protein that crossreacted with an antibody raised to native CsEXP1 fraction S1 (Li et al. 1993). We performed an immunoblot analysis of proteins extracted with high-salt buffer from uninoculated sweetclover roots, 20-day-old inoculated roots, and 20-day-old nodules (Fig. 6). The CsEXP1 antibody cross-reacted strongly with an approximately $25-\mathrm{kDa}$ polypeptide in the lanes containing protein isolated from inoculated roots or nodules. A faint crossreactive band, also at $25 \mathrm{kDa}$, was detected in the root protein extracts in addition to several less cross-reactive bands of variable molecular weights following overexposure of the blot to film. The CsEXP1 antisera also recognized in the three protein extracts an approximately $55-\mathrm{kDa}$ polypeptide, which may represent a homo- or heterodimeric expansin complex. Using the same antibody, a similar 55-kDa protein was detected in tomato (Rose et al. 2000).

Once we determined that the antibody directed against the cucumber native expansin cross-reacted with a white sweetclover protein, we performed immunohistochemistry to localize a putative expansin protein within mature nodules. Using immunofluorescence labeling, Figure $5 \mathrm{~F}$ through $\mathrm{H}$ shows that a protein which cross-reacts with the CsEXP1 antibody is most obviously localized to the cell walls of the cells of zone II, the invasion zone. The highest magnification shows expansin staining of the cell walls and intercellular spaces, a distribution similar to that observed by Zhang and Hasenstein (2000) for cucumber hypocotyls and maize roots (Fig. 5H). Some expansin staining, although patchy, was observed in the nodule cortex, zone I, and zone III, particularly in those cells along the periphery of the nodule (Fig. 5G). A higher magnification of the latter region showed that the cell walls of both bacteroid-containing cells and uninfected cells contained a putative expansin (Fig. $5 \mathrm{H}$ ). A pre-immune serum control is shown in Figure 5I. A control for autofluorescence (data not shown) was identical to Figure 5I in terms of showing no expansin staining.

In summary, expansin staining is found in the walls of nodule cells that are undergoing enlargement: some of the cells of the nodule cortex and zones I and III and most of the cells of zone II and interzone II-III.

\section{DISCUSSION}

In this study, we identified one $\alpha$-expansin gene in M. alba. The deduced expansin protein shows all the characteristics of $\alpha$-expansin, and its amino acid sequence is similar to other $\alpha$ expansins, particularly to legume $\alpha$-expansins. There is little similarity in the first 25 residues of the peptide sequence, which constitutes the signal peptide. The presence of signal peptides, predicted with the program SignalP, suggests that the encoded proteins are targeted to the endoplasmic reticulum, as is assumed for other members of the expansin gene family (Cosgrove 2000a). The mature protein (232 amino acid residues) contains, at the carboxyl terminus, four conserved tryptophans whose spacing resembles that of tryptophans in the cellulose-binding domains of cellulase. This region may be responsible for expansin binding to cellulose and related wall glycans (Shcherban et al. 1995). Three probable domains in expansin protein were postulated (Cosgrove 2000b): a classical signal peptide, a central catalytic domain, and a putative cellulose-binding domain at the carboxy-terminus of the protein. The binding domain anchors expansin to the surface of 

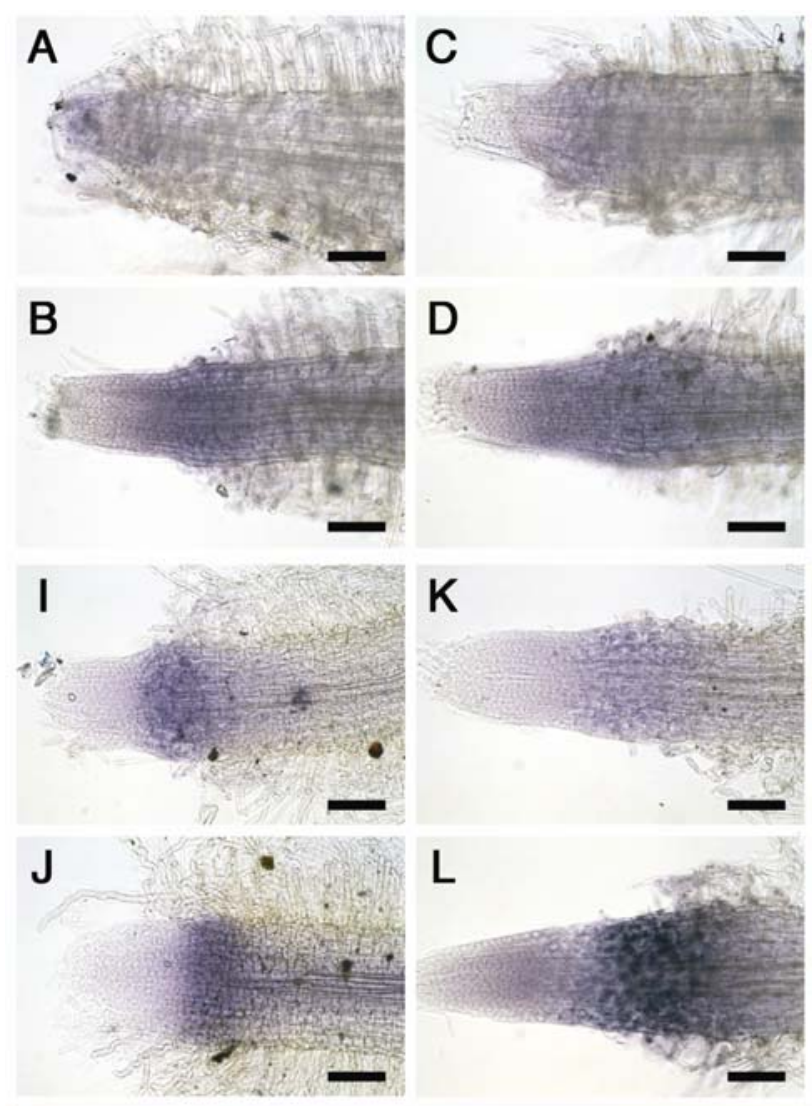

Q
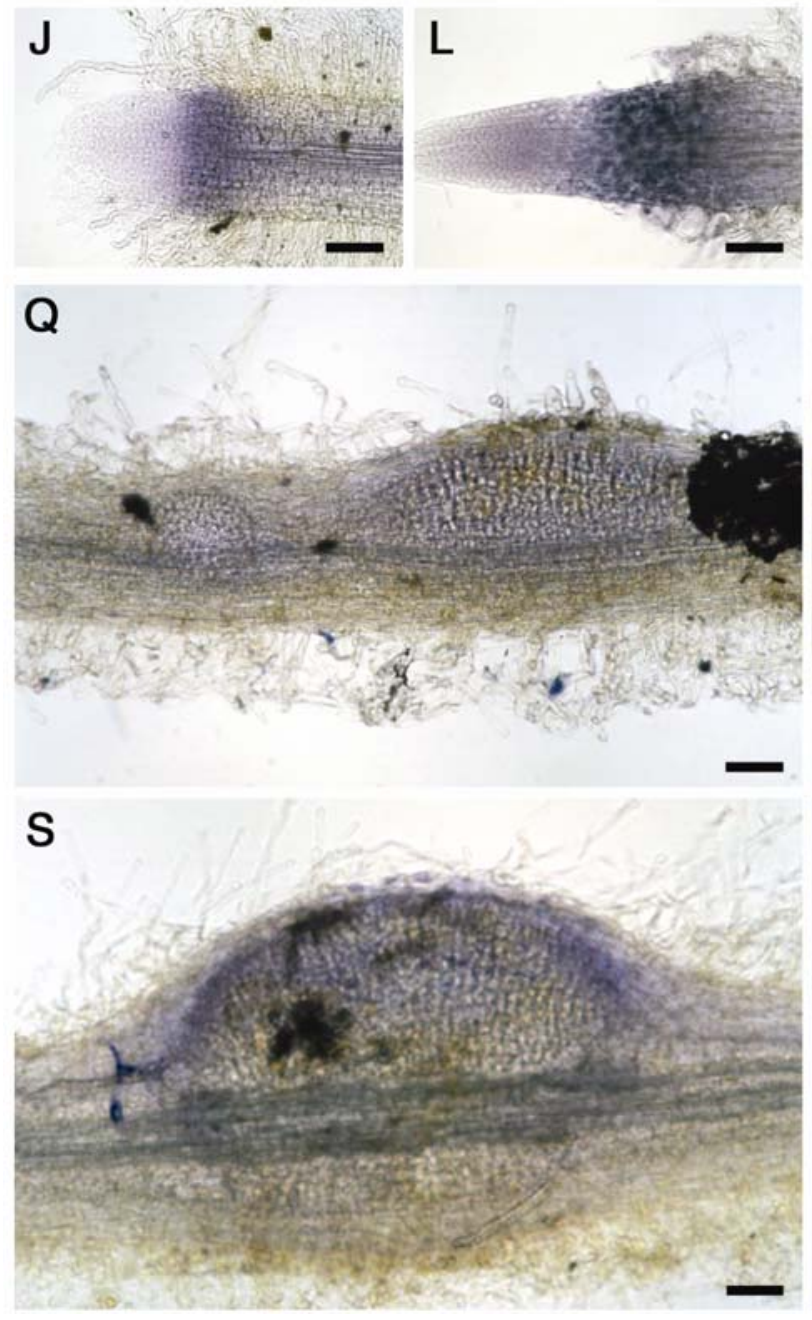

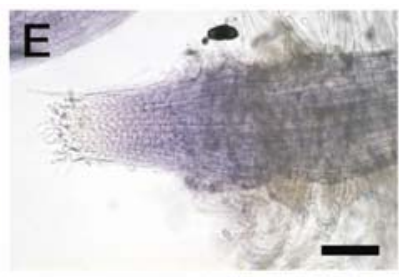

$\mathrm{F}$
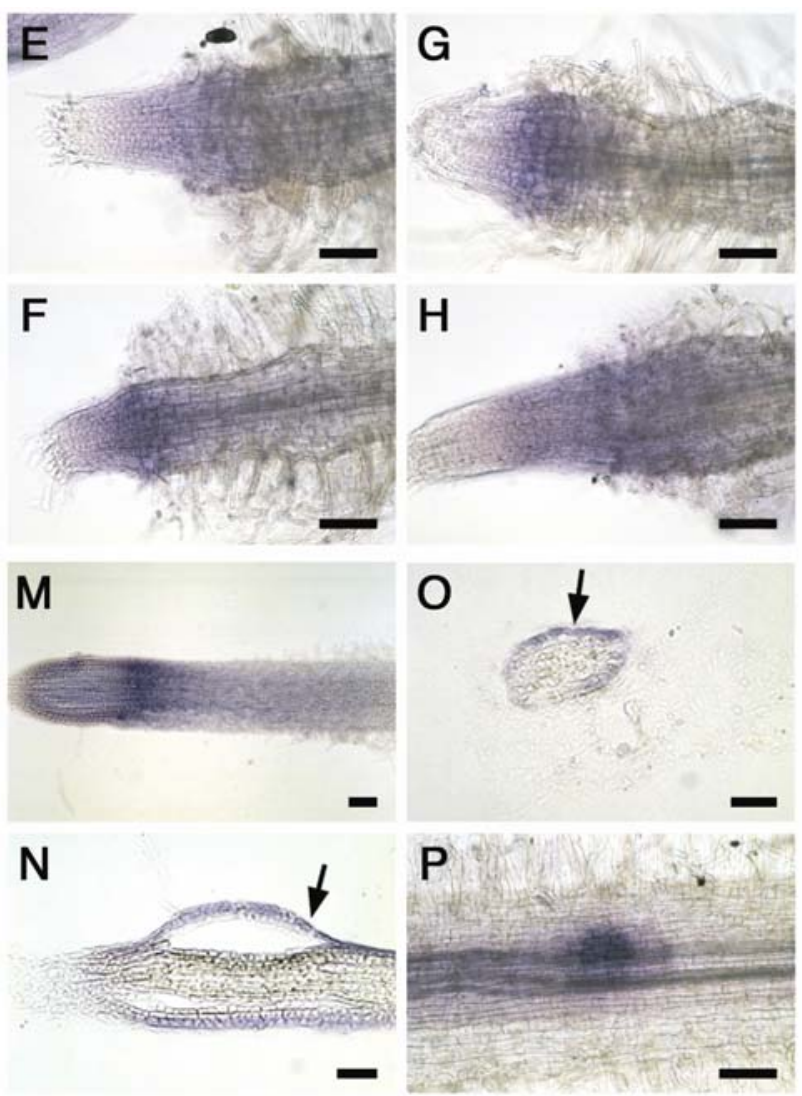

R
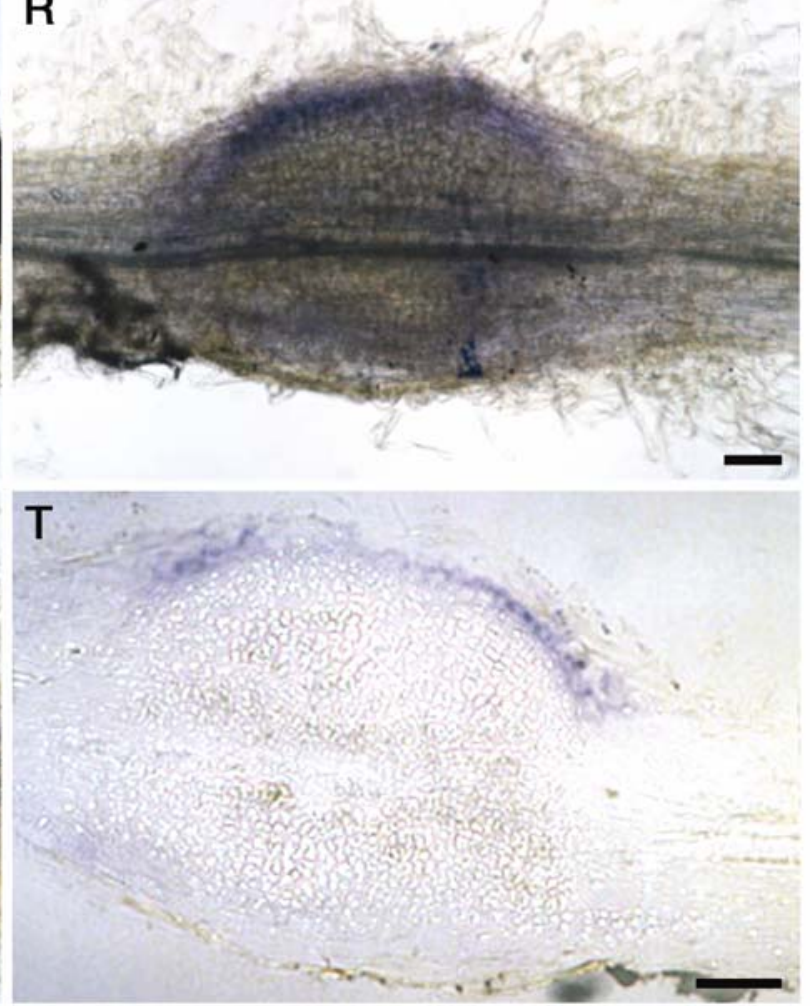

Fig. 3. Whole-mount in situ hybridization analysis used to localize MaEXP1 expression in roots and nodules of Melilotus alba. Pairs of roots either A, C, E, $\mathbf{G}, \mathbf{I}$, and $\mathbf{K}$, uninoculated or $\mathbf{B}, \mathbf{D}, \mathbf{F}, \mathbf{H}, \mathbf{J}$, and $\mathbf{L}$, inoculated with Sinorhizobium meliloti at $\mathbf{A}$ and $\mathbf{B}, 5$ hours post inoculation (hpi), C and $\mathbf{D}, 12 \mathrm{hpi}, \mathbf{E}$ and F, $24 \mathrm{hpi}, \mathbf{G}$ and $\mathbf{H}, 48 \mathrm{hpi}$, I and J, $72 \mathrm{hpi}$, and $\mathbf{K}$ and $\mathbf{L}, 4$ days post inoculation (dpi). M, Inoculated root 5 dpi. N, Longitudinal section of a root tip harvested $28 \mathrm{hpi}$. The root meristem and adjacent cells are faintly colored. The epidermis, which has peeled away from the root cortex, is stained bluepurple (arrow). O, Cross section of a lateral root. The epidermis (arrow) is intensely blue-purple. P, Not-yet emergent lateral root 4 dpi is stained bluepurple. Q, Region of root near the inoculation site (ink spot on the right). Both a lateral root and young nodule are stained blue-purple. R, A nodule 4 dpi. Blue-purple color indicating MaEXP1 transcript localization is in the outer cells of the nodule. S, A nodule 5 dpi showing a similar localization of MaEXP1 transcripts. T, The same nodule sectioned. Scale bar $=100 \mu \mathrm{m}$. 
the cellulose microfibril and restricts its mobility. This anchoring may be important to prevent expansins secreted by one cell from influencing the growth of neighboring cells. According to that model, and also because the growing cell wall of plants does not contain structural proteins that might play a role in parallel with the polysaccharide network, a recent report demonstrated that expansins lack proteinase activity and do not cause loosening via proteolysis ( $\mathrm{Li}$ and Cosgrove 2001).

Expansin genes have been cloned from many different plant species and tissues: a detailed list is continually updated by the Cosgrove laboratory at Penn State University (University Park, PA, U.S.A.). In general, expansins are members of a large gene family. In legumes, however, it is unclear as to how many family members exist. For example, in pea (PsEXP1) (Michael 1996) and in Medicago truncatula (Györgyey et al. 2000), only one expansin gene has been identified. Similarly, MaEXPl appears to exist as a single-copy gene although other, less closely related expansin genes, may occur in the Melilotus alba genome. In addition to a single $\beta$-expansin gene (Downes et al. 2001), the soybean $\alpha$-expansin genes, $G m E X P 1$ and $G m E X P 2$, have been reported to exist as singlecopy genes (Lee et al. 2003). Soybean is believed to be a diploidized tetraploid that was derived from an allotetetraploid ancestor (Zhu et al. 1994). This may explain why two singlecopy $\alpha$-expansin genes, GmEXP1 and $G m E X P 2$, were uncovered in the analysis of Lee and associates (2003). Also consistent with this hypothesis is the observation that, using an approach identical to the one described in this report to find expansin gene homologs in Medicago sativa cv. Iroquois, three different cDNAs with homology to $\alpha$-expansin were amplified (data not shown). Most alfalfa cultivars are autotetraploids derived from hybridizing $M$. sativa and $M$. falcata (Agricultural Research Service 1977). In contrast, white sweetclover like pea and M. truncatula is an autogamous diploid (Hirsch et al. 2000).

The newly identified Melilotus alba expansin gene, $M a E X P 1$, was amplified from cDNA derived from S. melilotiinoculated root RNA, and is highly expressed in root nodules induced by $S$. meliloti. MaEXP1 transcripts levels were lower in stem and root, and barely detected in leaves (Fig. 4). The increase in MaEXPl mRNA levels in nodules may be controlled at the level of gene transcription or mRNA stability. Northern blot analysis correlates specific times in nodule

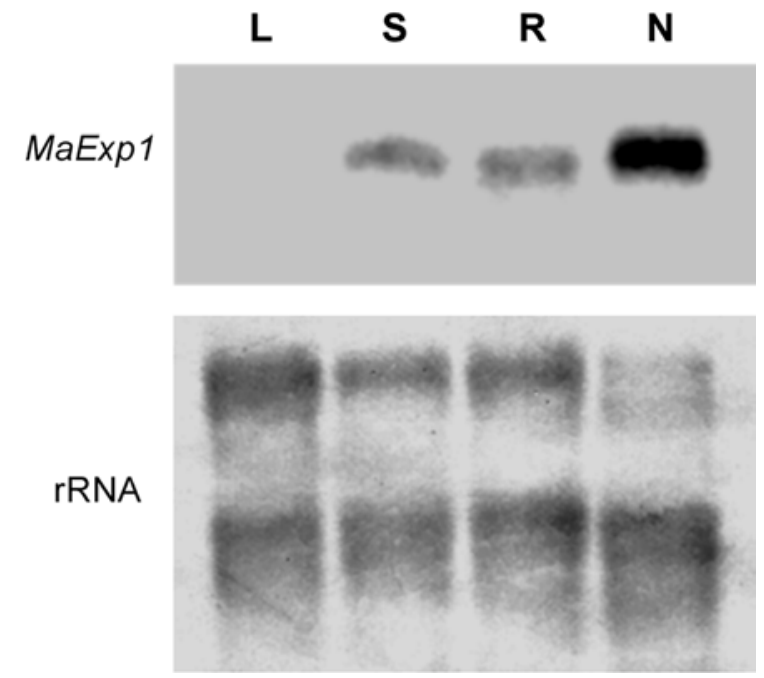

Fig. 4. Expression of expansin RNA in different white sweetclover tissues. A northern blot was prepared from $10 \mu \mathrm{g}$ of total RNA isolated from leaves $(\mathrm{L})$, stems $(\mathrm{S})$, roots $(\mathrm{R})$, and nodules $(\mathrm{N})$, which were collected 15 days post inoculation and probed with the $M a E X P 1$ probe. Amounts of ribosomal RNA were confirmed by staining the filter with methylene blue. development with the expression pattern of the MaEXPl gene. Analysis of transcript levels in roots soon after bacterial inoculation ( 0 to $48 \mathrm{~h})$ revealed no significant differences with respect to control roots (data not shown). However, WISH analysis, when used to study spot-inoculated roots, allowed us to observe augmented MaEXPl gene expression 5 hpi. The WISH studies enabled not only the visualization of this early increase in MaEXPl gene expression but also the accumulation of MaEXP1 transcripts in the elongation zone of the root, specifically in the root epidermis. However, at $24 \mathrm{hpi}$ and later time points, it was difficult to assess whether there were any major differences in gene expression between the control and inoculated samples.

As shown for other plant tissues, accumulation of expansin transcripts in white sweetclover correlates with proliferation and expansion activities of root and nodule tissues. Cho and Kende (1998) reported that, in rice, expansin transcripts are abundant in lateral root primordia. By using WISH analysis (Figs. 3 and 5), we demonstrated that MaEXP1 mRNAs, although present in root and nodule meristems, were abundant in the elongating or expanding tissues of young nodules and lateral roots. In mature nodules, MaEXP1 transcripts also were detected in cells that were expanding; these include young nodule cortex cells and the cells of the nodule meristem, the invasion zone, and interzone II-III. However, immunolocalization showed weak, patchy staining in the nodule cortex and meristem. In the case of the meristem, this may reflect the low level of transcript accumulation in zone I, but it also may result from the cells in this region being tightly packed. Zhang and Hasenstein (2000) suggested this possibility because they observed a similar lack of expansin staining in the maize root meristem. They also noted that staining was patchy unless the cell walls were partially digested with cellulase. We were able to detect putative expansin presence in the cell wells of the invasion zone and some of the cells of zone III without a cellulase pretreatment. However, as occurred in maize roots (Zhang and Hasenstein 2000), expansin staining becomes weaker with greater distance from the meristem. The discrepancy in transcript accumulation versus the patchy immunostaining of the inner cells of nodule cortex also might be explained by the tight packing of these cells or, alternatively, by some type of yet unknown post-translational regulation. More studies are needed.

Root hairs are unicellular extensions of root epidermal cells that develop near the root apex. To penetrate into the hosts via root hairs, rhizobia stimulate and reorientate the growth of root-hair cell walls, resulting in deformed and curled root hairs, indicating that expansin could be involved in this mechanism. Root hairs treated with Nod factor or rhizobia bear a strong resemblance to expansin-treated root hairs (Cosgrove et al. 2002). However, a crude Nod factor preparation did not cause a change in cell wall extensibility in a functional assay (D. J. Cosgrove, personal communication). Furthermore, in our studies, we detected MaEXPl transcripts in the root epidermis, but not reliably within root hairs. Similarly, Lee and associates (2003) did not report GmEXPl transcript localization in root hairs. In studies on maize root hairs, expansin protein was localized in the specialized epidermal cells that bulge out to form the root hair as well as at the apex of still elongating root hairs (Baluska et al. 2000). In addition, the expression of two Arabidopsis expansin genes was linked to root hair initiation (Cho and Cosgrove 2002). Expression in root hairs was detected using an AtEXP7 promoter linked to GUS or greenfluorescent protein (GFP) (Cho and Cosgrove 2002). AtEXP7 is a root-specific expansin in Arabidopsis. The possibility exists that such an expansin also exists in $M$. alba, based on the Southern blots where some faintly hybridizing bands were detected after low-stringency washes (data not shown). 
Legume nodules differ from lateral roots in their developmental origin, type of meristem, vasculature, hormone levels, and so on (Hirsch and LaRue 1997). However, in both nodules and emerging lateral roots, expansin transcript accumulation was observed in regions where cell elongation or expansion is taking place. This result suggests that expansin is one of several genes that are upregulated at common stages of lateral root and nodule development. However, other than the youngest cells of the nodule cortex, no peripheral tissue of the mature nodule accumulates $M a E X P l$ transcripts to the same extent as does the epidermis of the root. This points to a major developmental difference between roots and nodules.

Expression of specific expansin genes has been correlated with several physiological events, including hypocotyl expansion (McQueen-Mason et al. 1992), internode elongation in rice (Cho and Kende 1997), tomato fruit ripening (Rose et al. 1997, 2000), and leaf and root formation in rice (Cho and Kende 1998). To this list, we add expansin's participation in nodule morphogenesis.

\section{MATERIALS AND METHODS}

\section{Plant material.}

White sweetclover (M. alba Desr. U389) seed were surface sterilized as described (Löbler and Hirsch 1993) and germinated on mesh placed in Magenta Jars (Magenta Corp., Chicago), containing one-quarter-strength Hoagland's media without nitrogen, or aseptically germinated in a plastic pan containing vermiculite and perlite watered with one-quarter-strength nitrogen-free Hoagland's medium as previously described (Hirsch et al. 1989). The seedlings were inoculated 3 days after germination.

\section{Bacterial strain.}

White sweetclover plants were inoculated with wild-type S. meliloti (Rm1021) (Meade et al. 1982). The bacteria were grown in Rhizobium defined medium (Vincent 1970) until an optical density at $600 \mathrm{~nm}$ of 1.0 was reached. After washing the cells, $1 \mathrm{ml}$ of bacteria resuspended in Hoagland's medium was used per Magenta jar and $10 \mathrm{ml}$ of bacteria were used as inoculum per row of plants grown in the plastic pan. For the studies on spot inoculation, rhizobia harboring plasmids that drive the expression of the autofluorescent GFPs were used. The spot on the roots was made with a pulled-out glass capillary.

\section{Nucleic acid manipulations.}

Genomic DNA was extracted from leaves of $M$. alba as described by Dellaporta and associates (1983). Restriction enzyme digestions were performed under standard conditions. To examine the temporal patterns of MaEXPl gene expression or to produce cDNA using RT-PCR reactions, total RNA was isolated from different organs of $M$. alba. Tissues were harvested, frozen immediately in liquid nitrogen, and stored at $70^{\circ} \mathrm{C}$ until use (Löbler and Hirsch 1993). Total RNA was isolated using RNA STAT-60 (Tel-Test "B". Inc., Friendswood, TX, U.S.A.).

\section{Expansin gene isolation and sequence analysis.}

Total RNA ( $1 \mu \mathrm{g})$ from inoculated white sweetclover roots was used as template for cDNA synthesis using $0.5 \mathrm{mM}$ dNTPs, oligo $\mathrm{d}(\mathrm{T})_{12-18}$ at $25 \mu \mathrm{g} / \mathrm{ml}$, ribonuclease inhibitor at 2 units/ $\mu 1$, and Superscript II Reverse Transcriptase (GIBCO/ $\mathrm{BRL}$ ) at 10 units $/ \mu \mathrm{l}$ at $42^{\circ} \mathrm{C}$ for $60 \mathrm{~min}$. The reaction was inactivated by heating at $75^{\circ} \mathrm{C}$ for $15 \mathrm{~min}$. The products subsequently were diluted and used as template for PCR amplification.
Degenerate PCR primers were designed from conserved amino acids identified in an alignment of deduced amino acid sequence from nine expansins (Shcherban et al. 1995). The sense primer 5'-G(GC)(N)CA(TC)GC(N)AC(N) TT(TC) TA(TC) GG(N)G-3' corresponded to amino acids 6 to 11 of the consensus sequence, and the antisense primer $5^{\prime}$-(TC)TG CCA(AG)TT(TC)TG(N)CCCCA(AG)TT-3' to amino acids 182 to 188 ( $\mathrm{N}=\mathrm{A}, \mathrm{T}, \mathrm{C}$, or $\mathrm{G})$. The PCR amplification was carried out using $0.2 \mathrm{mM}$ dNTPs, $2.5 \mathrm{mM} \mathrm{MgCl} \mathrm{m}_{2}, 1 \mu \mathrm{M}$ each primer, and 2.5 units of Taq DNA polymerase (GIBCO/BRL). Amplification was performed by using an initial 5-min cycle at $94^{\circ} \mathrm{C}$, followed by 30 cycles of 30 -s denaturation at $94^{\circ} \mathrm{C}$, a 30 -s primer annealing at $55^{\circ} \mathrm{C}$, and a 90 -s elongation at $72^{\circ} \mathrm{C}$, concluding with a final $10 \mathrm{~min}$ at $72^{\circ} \mathrm{C}$ for extension. The PCR products were size fractionated on a $1.5 \%$ agarose gel. The resulting approximately 540-bp cDNA fragment was cloned into pT-Adv Vector (Clontech, Palo Alto, CA, U.S.A.) and 16 clones were sequenced. M13 forward and reverse sites in the plasmid were used to prime a sequencing reaction. To obtain full-length cDNA, a 5' and $3^{\prime}$ rapid amplification cDNA ends (RACE) procedure was performed with kits from Invitrogen (Carlsbad, CA, U.S.A.) according to the manufacturer's instructions. Based on the 537-bp sequence data, gene-specific primers were designed and used with the primers provided in the kits for amplifying $5^{\prime}$ ends and $3^{\prime}$ ends using PCR. The resulting DNA fragments for each PCR were purified, subcloned into the TOPO TA Cloning vector (Invitrogen), and sequenced at the University of California-Los Angeles Core Sequencing Lab. The 537-bp sequence and its corresponding 5'- and 3'-RACE sequences were combined to produce the full-length DNA sequence of $M a E X P 1$. For the sequence analysis, the predicted amino acid sequence for the $M$. alba expansin gene ( $M a E X P 1)$ was aligned with the corresponding sequences of expansins present in the GenBank database using the DNASTAR Megalign Clustal program.

\section{DNA and RNA gel-blot analysis.}

Genomic DNA was isolated from $M$. alba leaves. Genomic DNA $(10 \mu \mathrm{g})$ was digested with a range of restriction enzymes, fractionated by electrophoresis on $0.8 \%$ (wt/vol) agarose gels, and transferred to Nytran (Schleicher and Schuell) membranes. A 537-bp EcoRI fragment from the MaEXP1-14 cDNA clone was radiolabeled by random hexamer priming using $\left(\alpha-{ }^{32} \mathrm{P}\right)$ dATP and Klenow DNA polymerase and used as the MaEXPl probe. Blots were hybridized at $55^{\circ} \mathrm{C}$ in $5 \times$ Denhardt's solution, $5 \times \mathrm{SSPE}\left(1 \times \mathrm{SSPE}\right.$ is $0.18 \mathrm{M} \mathrm{NaCl}, 10 \mathrm{mM} \mathrm{NaPO}_{4}$, and $1 \mathrm{~nm}$ EDTA [pH 7.7]), $0.5 \%$ sodium dodecyl sulfate (SDS), and $50 \%$ (vol/vol) formamide. Washes were carried out at $65^{\circ} \mathrm{C}$ using $1 \times \mathrm{SSC}(1 \times \mathrm{SSC}$ is $0.15 \mathrm{M} \mathrm{NaCl}$ plus $0.015 \mathrm{M}$ sodium citrate), $0.5 \%$ SDS, and $0.1 \times$ SSC plus $0.5 \%$ SDS (twice for $15 \mathrm{~min}$ each).

Total RNA (10 $\mu \mathrm{g}$ per lane) was subjected to electrophoresis on $1 \%(\mathrm{wt} / \mathrm{vol}$ ) agarose, $10 \%$ formaldehyde gels (McKhann and Hirsch 1994), transferred to a membrane, and hybridized at conditions equivalent to that for the DNA-blot described above. RNA gels were visualized with ethidium bromide, or the RNA blotted to membranes was stained with methylene blue to test for equal loading.

\section{In situ hybridization.}

For preparing antisense and sense RNA fragments of the $M$. alba MaEXP1 gene, a cDNA fragment of 537 bp obtained by RT-PCR in the conditions described above was cloned into pCR II Vector (Invitrogen), giving plasmid MaEXP1-F. The probes were produced from T7 and SP6 RNA polymerase promoters, labeled with digoxigenin (DIG) by using the DIG 


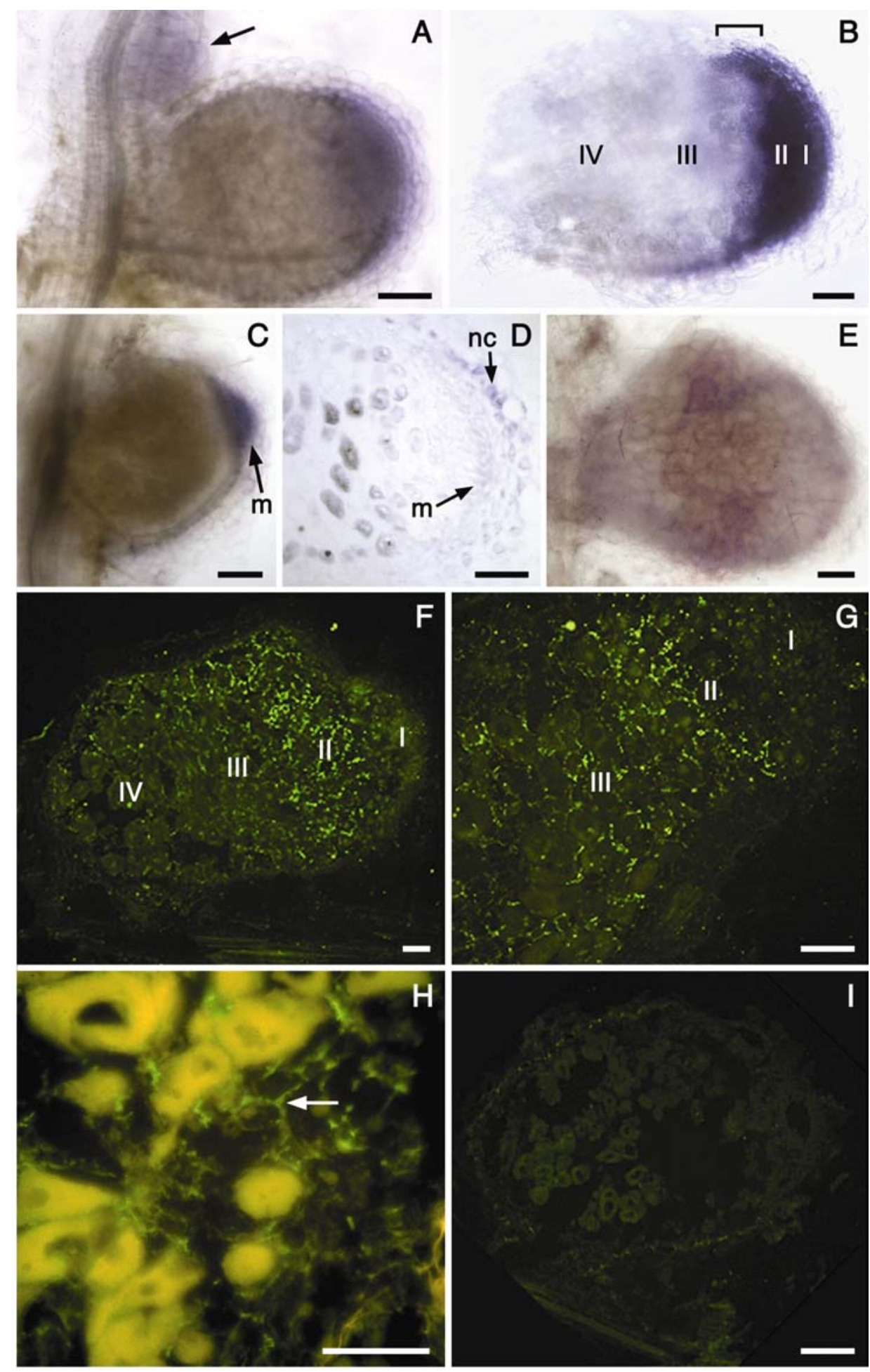

Fig. 5. Localization of MaEXP1 transcripts and distribution of expansin protein in sweetclover nodules. A through E, For the in situ hybridizations, the tissues were probed with digoxigenin-labeled antisense MaEXP1 RNA (A through D) or sense MaEXP1 RNA (E). A, Whole-mount in situ hybridization analysis of a nodule and nodule primordium (arrow) emerging from the same root 15 days post inoculation (dpi). B, Longitudinal section of nodule harvested 20 dpi showing the different nodule zones. MaEXP1 transcripts as evidenced by blue-purple color are found in the nodule cortex, zone I (meristem), and zone II (invasion zone), with a tapering off in zone III. Interzone II-III is bracketed. C, A nodule of approximately the same age as A but showing lesser accumulation of MaEXP1 transcripts. D, Section of a nodule $(10 \mu \mathrm{m})$ which was harvested $20 \mathrm{dpi}$, but shows a transcript accumulation pattern similar to C. MaEXP1 transcripts are detected in the inner cells of the nodule cortex (nc) and zone I (m). There is some blue-purple color in the infected cell zone. E, An intact nodule harvested $20 \mathrm{dpi}$ and hybridized with the sense probe. Scale bar $=100 \mu \mathrm{m}$. F through $\mathbf{H}$, Detection and distribution of expansin protein in sweet clover nodules. The tissues were incubated with antibodies raised to native CsEXP1; sections were 10 to $15 \mu \mathrm{m}$. F, A protein cross-reacting to CsEXP1 is detected primarily in the cell walls of the invasion zone. Patchy localization is observed in the nodule cortex, the meristem (I), and zone III of the nodule. Confocal micrograph. G, Enlarged view of another nodule showing a similar localization of a protein cross-reacting to CsEXP1 in the cell walls. In this nodule, some cross-reaction is observed in zone III, especially at the edge of the nodule. Confocal micrograph. H, Enlargement of cells in zone II showing accumulation of a protein cross-reacting to CsEXP1 in the cell walls and intercellular spaces. Because this is a light micrograph, there is significantly more autofluorescence of the bacteria-containing cells because of the longer exposure times compared with the confocal micrographs. I, No cross-reacting protein is detected in the pre-immune-serum control section. Scale bar $=100 \mu \mathrm{m}$. 
RNA-labeling kit from Boehringer Mannheim (Ridgefield, CT, U.S.A.), and degraded to approximately 150 nucleotides long before hybridization (McKhann and Hirsch 1993). White sweetclover nodules and roots were fixed, dehydrated, and finally hybridized to DIG-labeled antisense or sense RNA probes according to a procedure derived from de Almeida Engler and associates (1998) (Giordano et al. 2002). Five roots and 10 nodules were examined for each time point. Roots and nodules were embedded in paraffin and sectioned as described in McKhann and Hirsch (1993).

Photographs were taken with Kodak Ektachrome Tungsten 160 film on a Zeiss Axiophot microscope and scanned into the computer, and composites were made using Adobe Photoshop.

\section{Protein extraction, immunoblotting, and immunolocalization.}

Crude wall proteins were prepared as described (Wu et al. 1996). Frozen root or nodule tissue was ground to a powder in liquid nitrogen and thawed in ice-cold extraction buffer A (25 mM Hepes buffer [pH 6.8], 2 mM EDTA, 0.1\% Triton X100 , and $3 \mathrm{mM}$ sodium meta-bisulfite) and homogenized for $1 \mathrm{~min}$. The samples were centrifuged at $10,000 \times g$ for 30 min and the pellets washed three times by resuspending them in the same buffer without Triton X100 (extraction buffer B), followed by centrifugation. The pellets each were resuspended in buffer B plus $1 \mathrm{M} \mathrm{NaCl}$ and stirred at $4^{\circ} \mathrm{C}$ for $12 \mathrm{~h}$. Samples were centrifuged as before, the supernatants removed, the pellets re-extracted, and the supernatants combined. The solubilized fraction was precipitated by the addition of ammonium sulfate at $0.4 \mathrm{~g} \mathrm{ml}^{-1}$. The precipitated protein was resuspended in buffer $\mathrm{B}$, desalted, and concentrated with a Centricon YM-10 microconcentrator (Millipore, Bedford, MA, U.S.A.). Protein concentrations were determined with a protein assay kit (Bio-Rad, Hercules, CA, U.S.A.) using bovine serum albumin (BSA) as a standard. Protein extracts ( $40 \mu \mathrm{g} / \mathrm{lane})$ were separated by SDS-polyacrylamide gel electrophoresis on a $15 \%$ polyacrylamide gel (Bio-Rad) and transferred electrophoretically to a nitrocellulose membrane. The membrane was blocked with $3 \%$ BSA in phosphate-buffered saline (PBS) containing 0.1\% Tween 20 (PBS-T) and exposed sequentially to 1:1000 diluted rabbit anti-CsEXP1 antiserum (Li et al. 1993), followed by 1:5000 diluted anti-rabbit horseradish peroxidase-conjugated secondary antibody, and chemiluminescent reagents before exposure to Hyperfilm ECL (Amersham Life Science, Piscataway, NJ, U.S.A.). Intermediate washing steps were according to the manufacturer's instructions. Prestained molecular weight markers were from Novex (San Diego, CA, U.S.A.).

For the immunolocalization experiments, the nodules were fixed with $2.5 \%$ paraformaldehyde in stabilizing buffer $(0.1$ $\mathrm{M}$ cacodylate, $\mathrm{pH}$ 7.2) for $1 \mathrm{~h}$ at root temperature. They were briefly washed in PBS buffer (four times for $10 \mathrm{~min}$ each), embedded in O.C.T. (Tissue Tek; Electron Microscopy Supplies, Hatfield, PA, U.S.A.), and placed on dry ice. Longitudinal sections (10 to $15 \mu \mathrm{m}$ thick) were cut on a rotary Zeiss cryostat. Sections were blocked for $1 \mathrm{~h}$ at room temperature with 5\% BSA in PBS, incubated with primary antibody diluted in PBS (1:20 or 1:100) for $2 \mathrm{~h}$ at room temperature, and washed with $0.5 \%$ PBS-T. The expansin primary antibodies were stained with FITC-conjugated anti-rabbit secondary antibody diluted 1:200 in PBS for $1 \mathrm{~h}$ at root temperature. Fluorescence was examined using either a Zeiss Axiophot microscope or a Bio-Rad MRC1024ES (krypton-argon) confocal laser scanning microscope. The images were processed by Adobe Photoshop.

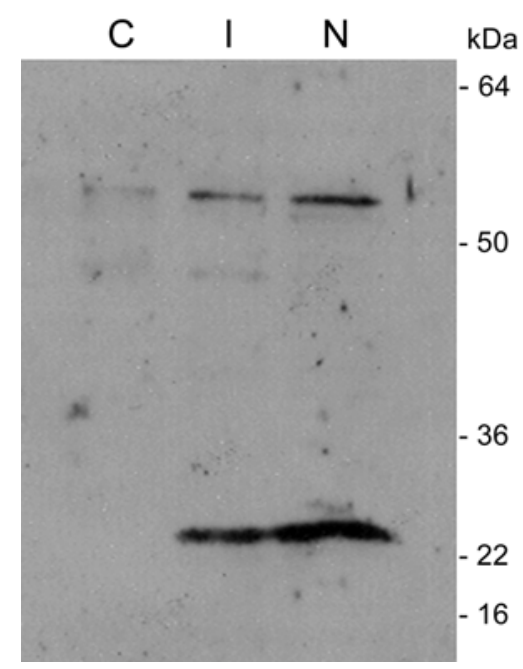

Fig. 6. Detection of expansin proteins in root and nodule tissues. Immunoblot analysis of expansin protein expression during nodule development on Melilotus alba roots (C), 20-day-old inoculated roots (I), and 20day-old nodules $(\mathrm{N})$. Membranes were incubated with antibodies raised to native CsEXP1. Size markers are indicated.

\section{ACKNOWLEDGMENTS}

This research was supported by UC-BIOSTAR grant S98-86 to A. M. Hirsch and by a CONICET (Argentina) fellowship to W. Giordano. We thank D. J. Cosgrove (Pennsylvania State University) for the expansin cucumber antibodies; H. J. Garbán and A. Luque Jimenez (University of California-Los Angeles) for help with the cloning experiments and Western blot analysis; N. A. Fujishige and N. Lee (University of California-Los Angeles) for help with the WISH protocol and immunolocalization experiments, respectively; our lab mates for their helpful comments on the manuscript; S. Lin is for the use of the Zeiss cryostat; and M. Kowalczyk for her expert help with the illustrations.

\section{LITERATURE CITED}

Agricultural Research Service. 1977. Alfalfa germplasm in the United States. Genetic vulnerability, use, improvement, and maintenance. U. S. Dept. Agric. Tech. Bull. No. 1571.

Altschul, S. F., Madden, T. L., Schäffer, A. A., Zhang, J., Zhang, Z., Miller, W., and Lipman D. J. 1997. Gapped BLAST and PSI-BLAST: A new generation of protein database search programs. Nucleic Acids Res. 25:3389-3402.

Baluska, F., Salaj, J., Jaideep, M., Braun, M., Jasper, F., Samaj, J., Chua, N.-H., Barlow, P. W., and Volkmann, D. 2000. Root hair formation: Facting-dependent tip growth is initiated by local assembly of profilinsupported F-actin meshwork accumulated within expansin-enriched bulges. Dev. Biol. 227:618-632.

Cho H.-T., and Cosgrove, D. J. 2002. Regulation of root hair initiation and expansin gene expression in Arabidopsis. Plant Cell 14:3237-3253.

Cho, H.-T., and Kende, H. 1997. Expansins in deepwater rice internodes. Plant Physiol. 113:1137-1143.

Cho, H.-T., and Kende, H. 1998. Tissue localization of expansins in deepwater rice. Plant J. 15:805-812.

Cosgrove, D. J. 1989. Characterization of long-term extension of isolated cell walls from growing cucumber hypocotyls. Planta 177:121130 .

Cosgrove, D. J. 1998. Cell wall loosening by expansins. Plant Physiol. 118:333-339.

Cosgrove, D. J. 1999. Enzymes and other agents that enhance cell wall extensibility. Annu. Rev. Plant Physiol. Plant Mol. Biol. 50:391-417.

Cosgrove, D. J. 2000a. New genes and new biological roles for expansins. Curr. Opin. Plant Biol. 3:73-78.

Cosgrove, D. J. 2000b. Expansive growth of plant cell walls. Plant Physiol. Biochem. 38:109-124.

Cosgrove, D. J., Li, L.C., Cho, H.-T., Hoffmann-Benning, S., Moore, R C., and Blecker, D. 2002. The growing world of expansins. Plant Cell Physiol. 43:1436-1444.

de Almeida Engler, J., van Montague, M., and Engler, G. 1998. Wholemount in situ hybridization in plants. Pages 373-384 in: Methods in 
Molecular Biology: Arabidopsis protocols. J. M. Martinez-Sapater and J. Salinas, eds. Humana Press Inc., Totowa, NJ, U.S.A.

Dellaporta, S. L., Wood, J., and Hicks, J. B. 1983. A plant DNA minipreparation: Version II. Plant Mol. Biol. Rep. 1:19-21

Downes, B. P., Steinbaker, C. R., and Crowell, D. N. 2001. Expression and processing of a hormonally regulated $\beta$-expansin from soybean. Plant Physiol. 126:244-252.

Downie, J. A., and Walker, S. A. 1999. Plant responses to nodulation factors. Curr. Opin. Plant Biol. 2:483-489.

Giordano, W., Lum, M. R., and Hirsch, A. M. 2002. Effects of a Nodfactor overproducing strain of Sinorhizobium meliloti on the expression of the ENOD40 gene in Melilotus alba. Can. J. Bot. 80:907-915.

Györgyey, J., Vaubert, D., Jiménez-Zurdo, J. I., Charon, C., Troussard, L., Kondorosi, A., and Kondorosi, E. 2000. Analysis of Medicago truncatula nodule expressed sequences tags. Mol. Plant-Microbe Interact. 13:62-71.

Hirsch, A. M., Bhuvaneswari, T. V., Torrey, J. G., and Bisseling, T. 1989. Early nodulin genes are induced in alfalfa root outgrowths elicited by auxin transport inhibitors. Proc. Natl. Acad. Sci. U.S.A.. 86:1244-1248.

Hirsch, A. M., and LaRue, T. A. 1997. Is the legume nodule a modified root or stem or an organ sui generis? Crit. Rev. Plant Sci. 16:361-392.

Hirsch, A. M., Lum, M. R., Krupp, R. S. N., Yang, W., and Karlowski, W. M. 2000. Melilotus alba Desr., white sweetclover, a mellifluous model legume. Pages 627-642 in: Prokaryotic Nitrogen Fixation: A Model System for the Analysis of a Biological Process. E. W. Triplett, ed. Horizon Scientific Press, Wymondham, U.K.

Kim, J. J., Cho, H.-T., and Kende, H. 2000. $\alpha$-Expansins in the semiaquatic ferns Marsilea quadrifolia and Regnellidium diphyllum: Evolutionary aspects and physiological role in rachis elongation. Planta 212:85-92.

Lee, D.-K., Ahn, J. H., Song, S.-K, Choi, Y. D., and Lee, J. S. 2003. Expression of an expansin gene is correlated with root elongation in soybean. Plant Physiol. 131:985-997.

Lerouge, P., Roche, P., Faucher, C., Maillet, F., Truchet, G., Promé, J. C., and Dénarié, J. 1990. Symbiotic host-specificity of Rhizobium meliloti is determined by a sulphated and acylated glucosamine oligosaccharide signal. Nature 334:781-784.

Li, Y., Darley, C. P., Ongaro, V., Fleming, A., Schipper, O, Baldauf, S. L., and McQueen-Mason, S. J. 2002. Plant expansins are a complex multigene family with an ancient evolutionary origin. Plant Physiol. 128:854-865

Li, Z.-C., and Cosgrove, D. J. 2001. Grass group I pollen allergens ( $\beta$-expansins) lack proteinase activity and do not cause wall loosening via proteolysis. Eur. J. Biochem. 268:4217-4226.

Li, Z.-C., Durachko, D. M., and Cosgrove, D. J. 1993. An oat coleoptile wall protein that induces wall extension in vitro and that is antigenically related to a similar protein from cucumber hypocotyls. Planta 191:349-356

Link, B. M., and Cosgrove, D. J. 1998. Acid-growth response and $\alpha$-expansins in suspension cultures of bright yellow 2 tobacco. Plant Physiol. 118:907-916.

Löbler, M., and Hirsch, A. M. 1993. A gene that encodes a proline-rich nodulin with limited homology to PSENOD12 is expressed in the invasion zone of Rhizobium meliloti-induced alfalfa nodules. Plant Physiol. 103:21-30.

McKhann, H. I., and Hirsch, A. M. 1993. In situ localization of specific mRNAs in plant tissues. Pages 179-205 in: Methods in Plant Molecular
Biology and Biotechnology. B. R. Glick and J. E. Thompson, eds. CRC Press, Inc., Boca Raton, FL, U.S.A.

McKhann, H. I., and Hirsch, A. M. 1994. Isolation of chalcone synthase and chalcone isomerase cDNAs from alfalfa (Medicago sativa L.): Highest transcript levels occur in young roots and root tips. Plant Mol. Biol. 24:767-777.

McQueen-Mason, S., and Cosgrove, D. J. 1994. Disruption of hydrogen bonding between plant cell wall polymers by proteins that induce wall extension. Proc. Natl. Acad. Sci. U.S.A. 91:6574-6578.

McQueen-Mason S., Durachko, D. M., and Cosgrove D. J. 1992. Two endogenous proteins that induce cell wall expansion in plants. Plant Cell 4:1425-1433.

Meade, H. M., Long, S. R., Ruvkun, G. B., Brown, S. E., and Ausubel, F. M. 1982. Physical and genetic characterization of symbiotic and auxotrophic mutants of Rhizobium meliloti induced by transposon $\mathrm{Tn} 5$ mutagenesis. J. Bacteriol. 149:114-122.

Metraux, T., and Taiz, L. 1977. Cell wall extension in Nitella as influenced by acids and ions. Proc. Natl. Acad. Sci. U.S.A. 74:1565-1569.

Michael, A. J. 1996. A cDNA from pea petals with sequence similarity to pollen allergen, cytokinin-induced and genetic tumour-specific genes: Identification of a new family of related sequences. Plant Mol. Biol. 30:219-224

Perret, X., Staehelin, C., and Broughton, W. J. 2000. Molecular basis of symbiotic promiscuity. Microbiol. Mol. Biol. Rev. 64:180-201.

Rose, J. K. C., and Bennett, A. B. 1999. Cooperative disassembly of the cellulose-xyloglucan network of plant cell walls: Parallels between cell expansion and fruit ripening. Trends Plant Sci. 4:176-183

Rose, J. K. C., Cosgrove, D. J., Albersheim, P., Darvill, A. G., and Bennett, A. B. 2000. Detection of expansin proteins and activity during tomato fruit ontogeny. Plant Physiol. 123:1583-1592.

Rose, J. K. C., Lee, H. H., and Bennett, A. B. 1997. Expression of a divergent expansin gene is fruit-specific and ripening-regulated. Proc. Natl. Acad. Sci. U.S.A. 94:5955-5960

Shcherban, T. Y., Shi, J., Durachko, D. M., Guiltinan, M. J., McQueenMason, S., Shieh, M. and Cosgrove, D. J. 1995. Molecular cloning and sequence analysis of expansins: A highly conserved, multigene family of proteins that mediate cell wall extension in plants. Proc. Natl. Acad. Sci. U.S.A. 92:9245-9249.

Vincent, J. M. 1970. A Manual for the Practical Study of Root-Nodule Bacteria. Blackwell Scientific Publications, London.

Wu, Y., Sharp, R. E., Durachko, D. M., and Cosgrove, D. J. 1996. Growth maintenance of the maize primary root at low water potentials involves increases in cell-wall extension properties, expansion activity, and wall susceptibility to expansins. Plant Physiol. 111:765-772.

Zhang, N., and Hasenstein, K. H. 2000. Distribution of expansins in graviresponding maize roots. Plant Cell Physiol. 41:1305-1312.

Zhu, T., Schupp, J. M., Oliphant, A., and Keim, P. 1994. Hypomethylated sequences: Characterization of the duplicate soybean genome. Mol. Gen. Genet. 244:638-645.

\section{AUTHOR-RECOMMENDED INTERNET RESOURCES}

Pennsylvania State University Cosgrove laboratory, Expansin Central webpage: www.bio.psu.edu/expansins

Center for Biological Sequence Analysis SignalP program: www.cbs.dtu.dk/services/SignalP 